\title{
Practice and Consideration on Hydromechanics teaching
}

\author{
Chen Feng-li Wu Da Zhang Lin \\ Air and Missile Defense College \\ Air Force Engineering University \\ Xi'an, China \\ 2030814638@qq.com
}

\begin{abstract}
Hydromechanics not only owns the strong theory, but also combines closely with the actual world. Characteristics such as multi-conception, strict logicality, abstraction and vapidity make it difficult to understand. Four aspects about Hydromechanics teaching are studied and discussed in this paper. They are reforming teaching mode, stimulating students' interest, optimizing the content and strengthening the practical teaching.
\end{abstract}

\section{Keywords-Hydromechanics; teaching; practice introduction}

Hydromechanics is an important professional basic course widely application, especially in aviation, aerospace, energy, power, machinery and other fields. The course has a significant position in the whole teaching system and it plays an important role on connecting the preceding phase and the following in the student's ability training and the knowledge structure system. But over the years, the effect of teaching is not very ideal, it has become consensus that teachers feel difficult to teach and students feel difficult to learn. The main reason is that teaching in the past depends on the traditional "four center" approach: take the classroom as the center, the degree of closure is high; take the book as the center, the degree of practice is weak; take the teacher as the center, the main body status of students is poor; take the instruction as the center, the contact of different subject is little. Students' interest in learning the course is at the low grade because of the traditional teaching methods and backward teaching condition. They can't feel the joy of learning from such boring theory knowledge, not to mention to cultivate and improve their comprehensive ability. Therefore, teachers should innovate their teaching idea, reform the teaching contents and methods based on seriously studying and accurate grasping of the course teaching rules. Teachers should not only teach the theory knowledge, but also ought to pay attention to the students' ability on using the theory to solve practical problems, so as to improve the quality of personnel training.

\section{CHANGE IDEAS AND REFORM PATTERNS}

\section{A. Change the education concept, pay attention to the cultivation of practical ability}

Teachers should change the educational ideas and teaching ideas, they must teach student knowledge, quality and ability training but not purely professional technical knowledge education, so that students are stimulated to solve practical problems with fluid mechanics method. Theoretical teaching should be integrated into the experimental teaching and numerical calculation, and the students can learn and explore in the basis of theoretical teaching. Teaching method and teaching means should be in line with actual needs of the theoretical problems. It is not demanded uniformity and it will be combined with the teacher's own specialty. Teachers should work out suitable method and means in line with the teaching rules and adapt to the students' characteristics. Through years of teaching we found that it is correct to contact the actual examples of life or engineering application as many as possible in the teaching process. If teachers outstands professional features, the students' learning interest can be greatly stimulated. Therefore, the center of the teaching should focus on the ability to cultivate the students' application of the knowledge to solve practical problems.

\section{B. Reform the teaching mode, pay attention to the cultivation of innovative thinking}

The change of teaching thought is reflected in the change of teaching mode. Teachers should get rid of the teaching mode of duck-feeding, they should put to use the inspiration and discussion type in teaching, and guide students observing phenomena, analyzing phenomena, summing up the law, then students will learn to engineering application. For example, when explaining the Bernoulli equation, teacher may introduce the phenomena of banana ball in football game at first; Then, teachers may raise his question: "Why the flight path of football is arc?" Step by step, based on fluid motion teacher guide the students to the differential Bernoulli equations through the question; Next step teacher may take the aircraft's tube for example to indicate how the equations is applied in practice; Finally teacher could encourage students to analyze other phenomena in life using Bernoulli equations, such as: why the roof is overturned by typhoon in south? Why we must stand outside the security line when waiting for the station? Why the pocket is turned out when washing? And so on.

Through this mode, the perceptual knowledge of students will be deepened. The students are guided from observing life phenomena to seeking problems actively. They will begin learning autonomously and not passively. Their learning enthusiasm will be greatly improved. 


\section{HAVE A DEFINITE OBJECT AND STIMULATE INTEREST}

Students are the object of education and the main body of the teaching activities, while the teacher is the leader of the teaching activity. To play a leading role better and mobilize the enthusiasm of students' learning, teachers must fully understand their students; know the specific circumstances of the students fairly well.

\section{A. Understand the students' characteristics, prepare the targeted preparation}

The first worked of most of the military academy students after graduating is the management of cadres. The students must spend a lot of time and energy for ideological political theory study, foundation courses and specialized courses, so time for study foundation course and professional course is relatively less compare with local college students. In view of these characteristics, in the teaching process, teachers should focus on understanding the theory and how to use the theory. The relevant theorem is given up. But there is need for the students to understand the general structure of the theoretical system as a whole, so that students can understand the theoretical system of the courses.

\section{B. Lead students to entry, stimulate study interest}

Interest is the best teacher, is the initial motivation of students' conscious learning. The object of Hydromechanics is students of undergraduate grade three. Two years before, the students study mainly the basic course, most of the students understand their major rarely and say nothing of understanding of the fluid. So they are filled with curious on their professional and eager to learn the professional teaching. At this point, the teacher should seize the students' curiosity to develop their passion for learning knowledge, to stimulate their learning enthusiasm from the use of the problem. For example, in the explanation of the introduction lesson, you can show brilliant achievements in the fields of science and engineering fluid mechanics though the picture; to the flow phenomena invisible to the eye, you can use of animation and video in the image reproducing, which can enrich the students perceptual knowledge of Hydromechanics and stimulate the students' thinking ability and imagination.

\section{SELECT CONTENTS AND OPTIMIZE RESOURCES}

\section{A. Cut out the superfluous, focus on the basic theory of moderation}

Hydromechanics is a professional basic course. Students have certain advanced mathematics and college physics knowledge, have certain logical reasoning and computing power. There are a lot of theoretical and deduction processes in Hydromechanics. Teacher should put the focus on the theoretical model and its physical meaning and application. A number of formulas are also obtained from the textbook, so what we should do is analyzing and sorting out from thinking and dilute the complicated mathematical deduction process. For example, when explaining orifice flow, the flow calculation formula has been concluded for energy equation. Therefore, teacher focuses on explaining the physical meaning of velocity coefficient and flow coefficient only. There are a lot of time left for teacher to explain other more important concept and theory and students have enough opportunity to think things out for themselves.

\section{B. Cut out the branchs, focus on the practical teaching contents}

In the course of optimizing the course contents, teachers must highlight the contents that have more engineering application, pay close attention to the professional course of the following. The contents can be divided into two parts, one is application of basic professional theory and the other is discipline system theory. In the teaching process, teachers should combine the basic theory to students' specialty and explain more practical knowledge closed related.

\section{Cut out the outmoded knowledge, focus on the novelty of teaching content}

Hydromechanics is a discipline which is both theoretical and practical. The contents of the following chapters are closely related to the engineering practice in particular. In order to make the knowledge of Hydromechanics course can be better used by students, over the past few years, through the teaching practice and society investigation, we have selected professional needs of content in refer to a large number of other college textbooks and technical data. In the meantime, we spread the content in engineering application of the depth and breath, and the latest scientific research is updated and enriched to the teaching. In the course of the selection and expansion of the contents, we put the focus on the theme of the novel, the content of the refining, the contents of the system coherence and gradual. In addition, we also pay close attention to the content for easy to understand, outstanding focus and difficulty.

\section{PAY ATTENTION TO PRACTICE AND STRENGTHEN EXPERIMENT}

The practice link should include the homework, the small thesis and the experiment.

\section{A. Pay attention to the training of exercises and explaining of examples}

Hydromechanics is a discipline that has strong practicality, so we focus on the ability of students to discovery problem, analyzing problem and solving problem. To achieve this purpose, teachers must not only explain lots of examples, but also arrange a considerable number of selection exercises to students, which enable students to change the death knowledge on books to their living ability through digestion and absorption. Therefore, teachers should arrange homework timely after class. No matter how busy, teachers should correct the homework all, and put right to the problem occurred in the operation.

\section{B. Write small thesis to cultivate students self-learning ability}

Teachers can leave some chapters to the students' self-study. The students need access to the information and writing a report based on the content. Such as the flow problem of orifice and nozzle, an engineering application requirements can be 
given to students, students is asked to design and calculation various nozzle self-completely, at last they should put forward the corresponding strategies.

\section{Comprehensive utilization of various experimental platforms}

Through experimental teaching, students can understand the basic concept and theory of classroom teaching, deepen know the flow problems and phenomena. Through experimental teaching, the interest in mathematical modeling of the actual problem is cultivated and the quantitative theoretical index system is gradually established. According to the basic teaching requirements of the project, the experimental process can divide the students into groups made of 2-3 persons, which can not only ensure to cultivate and explain actual operation ability of each student, but also improve the student ability to work in a team. In addition to the traditional experiments, we should also offer part of designing experiments and comprehensive experiments for the students. Under the guidance of teachers, these experiments is designed and completed by students independently access to information. After the experiments, the innovation ability of students has been greatly improved. Some phenomena that can't be demonstrated by experiment can be realized by the simulation experiment software. Simulation experiment can improve the students' comprehensive ability through combination of various experimental methods.

\section{CONCLUSION}

As a professional basic course, Hydromechanics has both strong theoretical and engineering actual close union. Teachers should not only transfer knowledge to the students in the teaching process, but also ought to pay more attention to cultivate students' ability of theory analysis and solution actual problem. The final purpose is to improve the professional quality of students and build solid foundation for study and work in the future.

\section{REFERENCES}

[1] Xiao Shujie. An Inquiry into the Reform of "Fluid Mechanics" in Civil Engineering Major [J]. Science educ, 2012, (11):34-35.

[2] Zhu Huibing. Reform and Innovation of Experiments Teaching in Engineering Hydrodynamics [J]. Journal of NingBo University, 2008, (2):109-111.

[3] Wang MingBo. Teaching Research and Application of Fluid Dynamics Basic Course [J]. Journal of Weifang University, 2009, (11):141-142.

[4] $\mathrm{Li}$ Xin. Problems and Countermeasures on the Teaching of Fluid Mechanics [J]. Journal of ShenYang College of Education, 2011, 13(2):54-55. 